\title{
Sensing behavior of silica-coated Au nanoparticles towards nitrobenzene
}

\author{
Suman Singh • Pooja Devi • Deepak Singh • \\ D. V. S. Jain • M. L. Singla
}

Published online: 2 June 2012

(C) The Author(s) 2012. This article is published with open access at SpringerLink.com

\begin{abstract}
In the present work, we report silica-stabilized gold nanoparticles $\left(\mathrm{SiO}_{2} / \mathrm{Au} \mathrm{NPs}\right)$ as a wide-range sensitive sensing material towards nitrobenzene (NB). Surface hydroxyl groups of silica selectively form Meisenheimer complex with electron-deficient aromatic ring of NB and facilitate its immobilization and subsequent catalytic reduction by Au cores. Silica-coated Au NPs were synthesized and characterized for their chemical, morphological, structural, and optical properties. $\mathrm{SiO}_{2} / \mathrm{Au}$ NPs-modified electrodes were characterized with impedometric and cyclic voltammetric electrochemical techniques. $\mathrm{SiO}_{2} / \mathrm{Au}$ NPs are found to have a higher optical detection window of range, $0.1 \mathrm{M}$ to $1 \mu \mathrm{M}$ and a lower electrochemical detection window of range, $10^{-4}$ to $2.5 \times 10^{-2} \mathrm{mM}$ with a detection limit of $12.3 \mathrm{ppb}$. A significant enhancement in cathodic peak current, $C_{1}$, and sensitivity $(102 \mu \mathrm{A} / \mathrm{mM})$ was observed with modified electrode relative to bare and silicamodified electrodes. The $I_{\mathrm{P}}$ was found to be linearly corelated to NB concentration $\left(R^{2}=0.985\right)$. The interference of cationic and anionic species on sensor sensitivity was also studied. Selectivity in the present sensing system may be further improved by modifying silica with specific functional moieties.
\end{abstract}

S. Singh $\cdot$ P. Devi $\cdot$ M. L. Singla $(\bowtie)$

Central Scientific Instruments Organization,

Chandigarh, India

e-mail: singla_csio@yahoo.com

D. Singh

Indian Institute of Pulses Research, (IIPR),

Kanpur, India

D. V. S. Jain

Panjab University,

Chandigarh, India
Keywords Silica-coated Au NPs $\cdot$ Impedance · Sensitivity $\cdot$ NB

\section{Introduction}

Nitrobenzene (NB) is a widely used solvent in manufacturing processes and is often discharged by industries as a waste. Increased industrial development and increased discharge of waste is resulting in surface and ground water pollution. NB is a high priority pollutant in the nitroaromatics (NACs) declared by the Environment Protection Agency on the basis of its known carcinogenicity, mutagenicity, and acute toxicity $[1,2]$. Conventional analytical methods used for the detection of NB include liquid-liquid extraction-gas chromatography, solid phase microextraction, nuclear quadrupole resonance, and electron capture techniques [3-7]. These techniques are highly selective and sensitive but are very expensive, laborious, and time consuming. Nanomaterials of size few to $100 \mathrm{~nm}$ have enabled new types of sensors that are capable of detecting extremely small amounts of analytes in lower limit range [8, 9]. However, nanoparticles (NPs) suffer from the aggregation problems, which revert them back to the bulk materials. To prevent agglomeration, metal NPs are often coated with ligands, polymers, organic surfactants, mesoporous/nanoporous supports, which not only delimit the particle size but also help in immobilization of the resulting NPs [10-12]. Owing to the large internal surface area and small pore size, mesoporous material finds applications in catalysis, chromatography supports, optics, photonics, semiconductor devices, and chemical sensors [13]. In the present work, polyvinylpyrollidone (PVP)-coated gold nanoparticles (Au NPs) have been synthesized and then functionalized with silica for NB detection. The formation of PVP and the silica 
layer on the particle surface helps in increasing the aggregation stability of the NPs by decreasing the inter phase tension via strengthening interactions between the dispersed phase and the dispersion medium. This in turn increases the entropy component of the system due to the involvement of molecules and ions of the surface layer in thermal motion together with particles of the dispersed phase [14]. Additionally, porous silica helps in the adsorption of analytes. Silica minerals are reported as one of the most efficient adsorbents for NACs contaminants [15].

Herein, we are reporting $\mathrm{SiO}_{2} / \mathrm{Au}$ NPs as a dynamic range sensor towards NB.

\section{Experimental details}

\section{Materials}

All chemicals were of analytical grade and used as received without further purification: $\mathrm{HAuCl}_{4}$ (Spectrochem Pvt. Ltd., Mumbai, India), PVP (Sisco Research Lab, Mumbai, India), tetraethyl orthosilicate (TEOS, Merk Specialties Pvt. Ltd., Darmstadt, Germany), ammonium hydroxide (S.D. Fine Chem. Ltd., Mumbai, India), ethanol (Changshu Yangyuan Chemical China, Changshu, China), ethylene glycol (Loba Chemie, Mumbai, India), and NB (Spectrochem Pvt. Ltd.). De-ionized water obtained from Millipore was used for all synthesis and experimental studies.

\section{Preparation of $\mathrm{SiO}_{2} / \mathrm{Au} \mathrm{NPs}$}

$\mathrm{Au}$ NPs were synthesized using hydrazine hydrate reducing agent and PVP capping agent. Briefly, PVP (1 g) was added into distilled water $(50 \mathrm{ml})$ under continuous stirring with following additions of $1 \% \mathrm{HAuCl}_{4}$ solution $(5 \mathrm{ml})$. To this mixture, hydrazine hydrate $(1 \mathrm{ml})$ was added and stirred until the appearance of wine red color which confirms the formation of Au NPs. Synthesized Au NPs were functionalized by silica using $\mathrm{Lu}$ et al. approach [11]. Briefly, $\mathrm{Au}$ NPs colloidal solution $(4 \mathrm{ml})$ was added to ethanol $(20 \mathrm{ml})$ under constant stirring followed by addition of ammonium hydroxide and TEOS $(5-10 \mu \mathrm{l})$. This solution was stirred at room temperature for about $1 \mathrm{~h}$ and then centrifuged at $8,000 \mathrm{rpm}$ for $30 \mathrm{~min}$ to collect coated NPs. Figure 1 shows

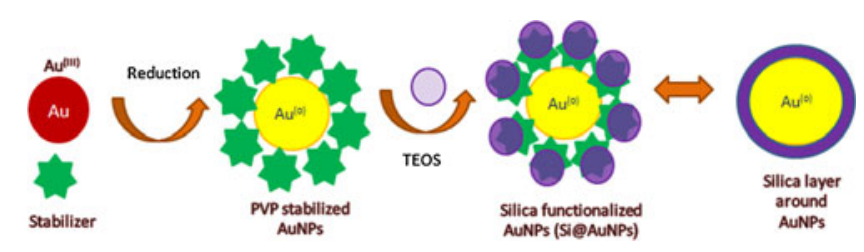

Fig. 1 Schematic for synthesis of $\mathrm{SiO}_{2} / \mathrm{Au}$ NPs the pictorial presentation of steps used in the synthesis and silica coating of $\mathrm{Au}$ NPs.

For electrochemical sensing, NB stock solution was prepared in acetonitrile and $\mathrm{NaCl}(0.1 \mathrm{M})$ was used as an electrolytic medium. Varying amounts $(1-300 \mu \mathrm{l})$ of NB $(0.01 \mathrm{mM})$ was added to the electrolyte solution and mixed properly prior to each voltammetric measurement.

Instrumentation

Optical studies were done using PerkinElmer ${ }^{\circledR}$ Lamda 35 UV-visible spectrophotometer. Scanning electron microscope (SEM) and energy-dispersive $\mathrm{x}$-ray analysis (EDXA) analysis was carried out on FE-SEM (Oxford Company) equipped with an X-ray analyzer for morphological and elemental information. Glassy carbon (GC) electrode spin coated with $\mathrm{SiO}_{2} / \mathrm{Au}$ NPs was used as working electrode for voltammetric and impedance studies in $0.1 \mathrm{MK}_{3}\left[\mathrm{Fe}(\mathrm{CN})_{6}\right] /$ $\mathrm{KCl}$ solution (used as a redox probe) using the $\mathrm{CHI}-660$ Instrument.

\section{Results and discussion}

\section{Characterization of $\mathrm{SiO}_{2} / \mathrm{Au} \mathrm{NPs}$}

Figure 2 shows EDXA spectrum of $\mathrm{SiO}_{2} / \mathrm{Au}$ NPs indicating presence of both $\mathrm{Au}(\mathrm{AuM}, 2.2 ; \mathrm{AuL}, 10.0 \mathrm{keV})$ and silica (SiK, $1.5-1.8 \mathrm{keV}$ ) along with a prominent peak for copper $(\mathrm{CuK}, 8.2 \mathrm{KeV}$; $\mathrm{CuL}, 0.9 \mathrm{KeV})$ which is possibly due to $\mathrm{X}$-ray emission from the copper substrate. EDXA spectra were collected over random areas to monitor the homogeneity of elemental composition. The presence of $\mathrm{Au}$ and silica peaks is consistent with the formation of silica shell on Au NPs. Inset shows the transmission electron microscopy (TEM) image of $\mathrm{SiO}_{2} / \mathrm{Au}$ NPs at high resolution confirming coating of Au NPs with silica. It can be clearly seen that the size of Au NP is around $\sim 38 \mathrm{~nm}$ and shell is of thickness $\sim 18 \mathrm{~nm}$.

Figure 3 shows UV-visible spectrum of $\mathrm{Au}$ (a) and $\mathrm{SiO}_{2} /$ $\mathrm{Au}$ NPs (b and c). The surface plasmon resonance (SPR) peak position at $528 \mathrm{~nm}$ confirms the formation of spherical $\mathrm{Au}$ nanoparticles [12]. A shift of $\sim 3 \mathrm{~nm}$ was observed on coating synthesized Au NPs with silica and is attributed to the change in the refractive index of the surrounding medium from 1.36 (ethanol) to 1.45 (silica) [16]. On further increasing TEOS amount ( 5 to $10 \mu \mathrm{l}$ ) for silica coating, no change in SPR peak position is observed, however, the intensity of SPR band increased (Fig. 3). This might be because of the increased scattering from thicker shells. The broadening of the SPR band after coating can be attributed to the roughness of the shell surface or the presence of a few particles with incomplete shells as earlier reported by $\mathrm{Lu}$ et al. $[13,17]$. 
Fig. 2 EDXA spectrum of $\mathrm{SiO}_{2} / \mathrm{Au}$ NPs (inset: $(a)$ SEM image of $\mathrm{SiO}_{2} / \mathrm{Au}$ NPs corresponding to EDXA spectrum and $(b)$ TEM image of $\mathrm{SiO}_{2} / \mathrm{Au} \mathrm{NP}$ at higher resolution)

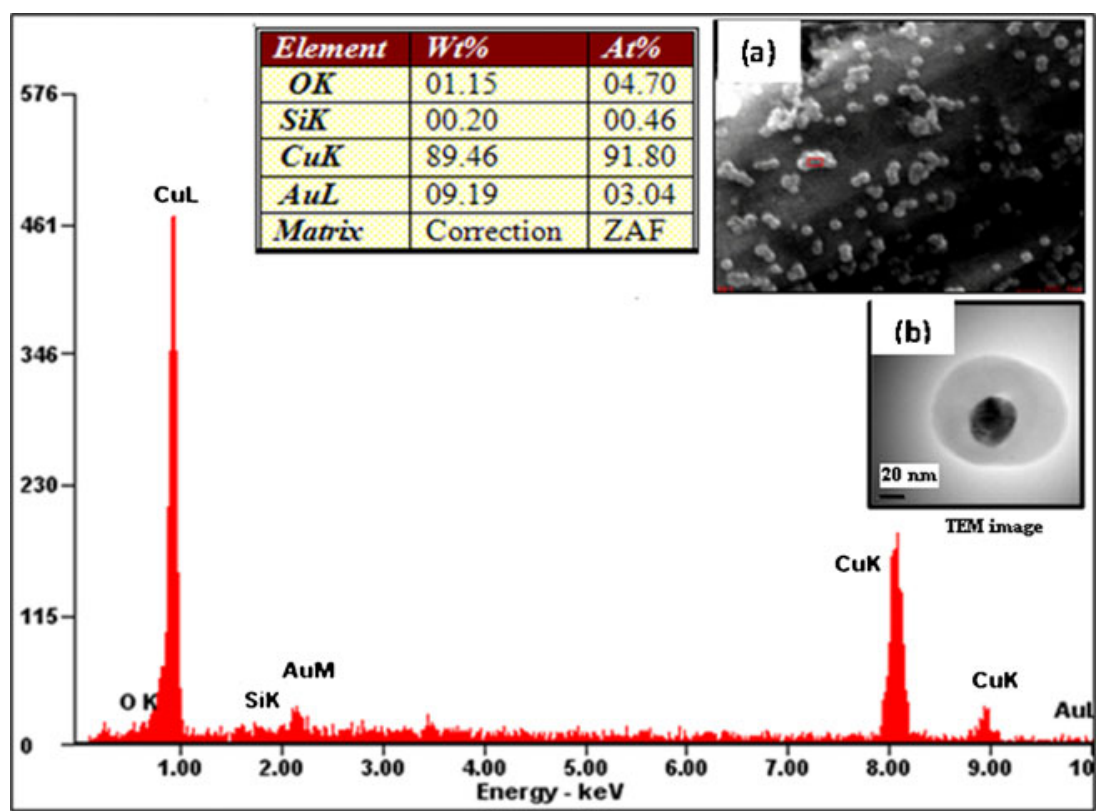

Characterization of $\mathrm{SiO}_{2} / \mathrm{Au}$ NPs-modified electrode

\section{Impedance and voltammetric studies}

Figure 4 shows interfacial features of bare (GC) and modified $\left(\mathrm{GC} / \mathrm{SiO}_{2} / \mathrm{Au} \mathrm{NPs}\right)$ electrodes in $0.1 \mathrm{MK}_{3}\left[\mathrm{Fe}(\mathrm{CN})_{6}\right] /$ $\mathrm{KCl}$ solution. Nyquist plot (real $\left(Z^{\prime}\right)$ vs. imaginary parts $\left(Z^{\prime \prime}\right)$ of the impedance) of $\mathrm{SiO}_{2} / \mathrm{Au}$ NPs-modified electrode $(\mathrm{GC} /$ $\mathrm{SiO}_{2} / \mathrm{Au}$ NPs) shows somewhat flattened semicircle at higher frequencies and a straight line forming an angle of $45^{\circ}$ to the real axis at lower frequencies. The flattened circle is a consequence of roughness due to the material $\left(\mathrm{SiO}_{2} / \mathrm{Au}\right.$ NPs) deposited on the electrode surface. A perfect semicircle corresponds to perfectly smooth surface and this circularity decreases with an increase in surface roughness
$[18,19]$. The straight line at lower frequencies can be attributed to the Warburg impedance which becomes dominant at lower frequencies for diffusion limited processes. Its appearance for modified electrode $\left(\mathrm{GC} / \mathrm{SiO}_{2} / \mathrm{Au} \mathrm{NPs}\right)$ may be due to the presence of insulating silica coating around $\mathrm{Au}$ NPs, which may partially limit the transport of ions to the electrode surface as indicated by increase in charge transfer resistance $\left(R_{\mathrm{ct}}\right)$ of the bare electrode from $1.88 \times 10^{2}$ to $2.51 \times 10^{2}$ after modification. This increase in $R_{\mathrm{ct}}$ value is possibly due to the steric hindrance and electrostatic repulsion between surface $\mathrm{SiO}_{2}{ }^{-}$groups and negatively charged redox couple [20,21].

Figure 5 shows cyclic voltamograms of bare (GC) and modified $\left(\mathrm{GC} / \mathrm{SiO}_{2} / \mathrm{Au} \mathrm{NPs}\right)$ electrodes in $0.1 \mathrm{MK}_{4}(\mathrm{Fe}$ $\left.(\mathrm{CN})_{6}\right)+\mathrm{KCl}$ solution. Cyclic voltammogram $(\mathrm{CV})$ of
Fig. 3 UV-visible spectra of (a) Au NPs and $(b, c) \mathrm{SiO}_{2} /$ $\mathrm{Au}$ NPs synthesized with varying TEOS amount, $5 \mu \mathrm{l}$ and $10 \mu \mathrm{l}$, respectively






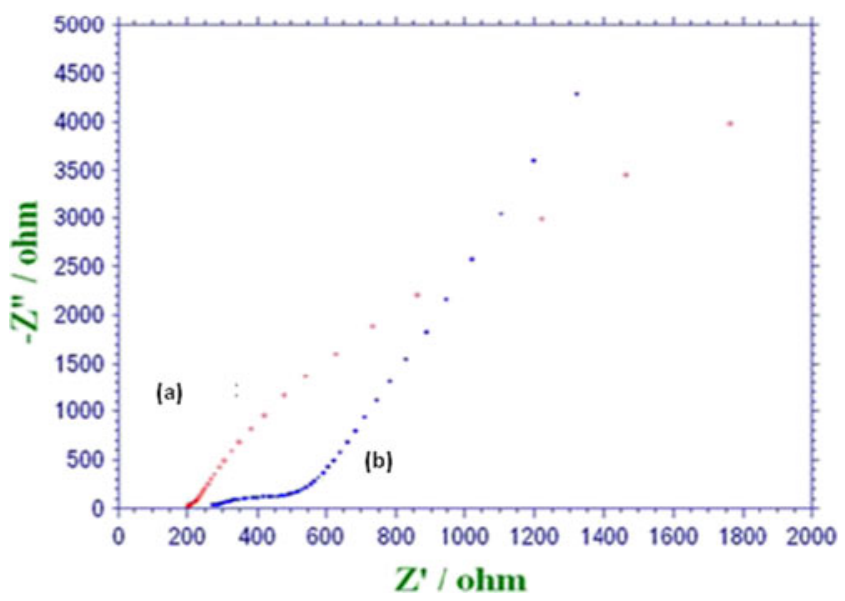

Fig. 4 Nyquist Plot of $(a)$ bare $\mathrm{GC}$ and $(b) \mathrm{SiO}_{2} / \mathrm{Au}$ NPs-modified GC electrode in $0.1 \mathrm{M}\left[\mathrm{K}_{4} \mathrm{Fe}(\mathrm{CN})_{6}+\mathrm{KCl}\right]$ solution

modified electrode in ferricyanide solution is a valuable tool to monitor the barrier of the modified electrode since the electron transfer between the solution species and the electrode must occur either through the barrier itself by tunneling or through the defects in the material/barrier. It is well proved that when the bare electrode surface is modified by somematerials, theelectron-transferkineticsofFe $(\mathrm{CN})_{6}{ }^{4-\prime}$

${ }^{3-}$ is perturbed.

It can be clearly seen from Fig. $5 \mathrm{a}, \mathrm{b}$ that the $\mathrm{CV}$ response of the bare GC electrode shows only one oxidation peak $\left(\mathrm{Fe}^{+2}\right.$ to $\left.\mathrm{Fe}^{+3}\right)$ whereas modified $\left(\mathrm{GC} / \mathrm{SiO}_{2} / \mathrm{Au} \mathrm{NPs}\right)$ electrode shows the presence of a proper redox couple for $\mathrm{Fe}^{2+} /$ $\mathrm{Fe}^{3+}$ ions with an enhanced current sensitivity $(102 \mu \mathrm{A} /$ $\mathrm{mM}$ ) relative to the bare GC (inset of Fig. 5b). This appearance of a redox couple and increase in the current signal for modified electrode could be explained by the increase in the effective electrode surface area because of modification with NPs [22]. Peak current $\left(I_{\mathrm{P}}\right)$ increases linearly with the square root of scan rate which indicates the dominance of diffusion in this electrochemical process. This behavior can be explained by Randles Sevick equation [23].

$i_{p}=2.69 \times 10^{5} n^{\frac{3}{2}} A D^{\frac{1}{2}} C v^{\frac{1}{2}}$

From the above equation, the diffusion coefficient $(D)$ for modified electrode is found to be $1.93 \times 10^{-8} \mathrm{~cm}^{2} / \mathrm{s}$.

\section{Detection of NB}

\section{Optical detection}

The optical detection of NB using $\mathrm{SiO}_{2} / \mathrm{Au}$ NPs is based on the change in the intensity of the SPR band of NPs after incubation with NB and is basically based on adsorption chemistry. Because of high mesoporosity and surface roughness resulting in a large surface-to-volume ratio, $\mathrm{SiO}_{2} / \mathrm{Au}$ NPs offer a vast surface area for efficient interaction with the analyte. In the presence of NB, intensity of the SPR band of $\mathrm{SiO}_{2} / \mathrm{Au}$ NPs decreases with no effect on band position (Fig. 6).

In our case, this sensing might be due to the interaction between $-\mathrm{NO}_{2}$ groups of $\mathrm{NB}$ and surface hydroxyls present on the silica surface. This interaction results in the formation of Meisenheimer complex which is a $\sigma$-complex formed by covalent addition of nucleophile to an arene carrying electron deficient aromatic compound. Since NB is electron deficient due to the strong electron withdrawing effect of $\mathrm{NO}_{2}$ group, NB is able to form Meisenheimer complex. From available literature, it is evident that such an interaction has been a

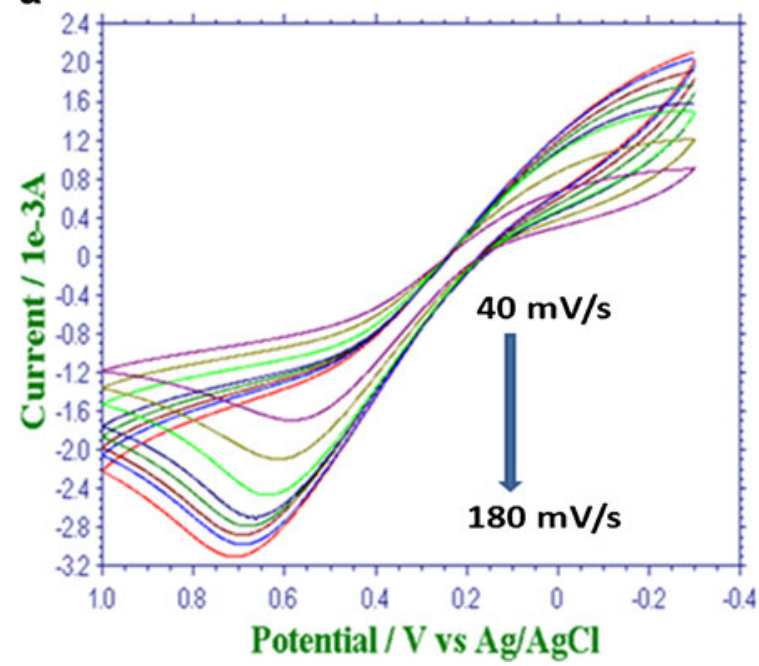

b

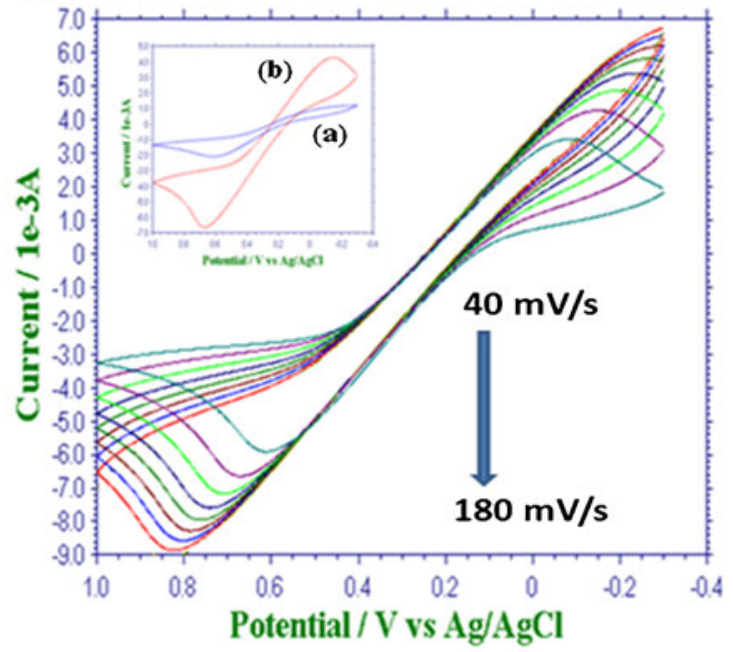

Fig. $5 \mathrm{CV}$ of $(a)$ bare $\mathrm{GC}$ and $(b) \mathrm{SiO}_{2} / \mathrm{Au}$ NPs-modified $\mathrm{GC}$ electrode in $0.1 \mathrm{M}\left[\mathrm{K}_{4} \mathrm{Fe}(\mathrm{CN})_{6}+\mathrm{KCl}\right]$ solution as a function of scan rate (40 to $180 \mathrm{mV} / \mathrm{s}$ ), inset: an overlay of bare GC (blue curve) and $\mathrm{Si} @ \mathrm{Au} \mathrm{NPs} / \mathrm{GC}$ (red curve) response in $\mathrm{K}_{4} \mathrm{Fe}(\mathrm{CN})_{6}$ electrochemical solution 


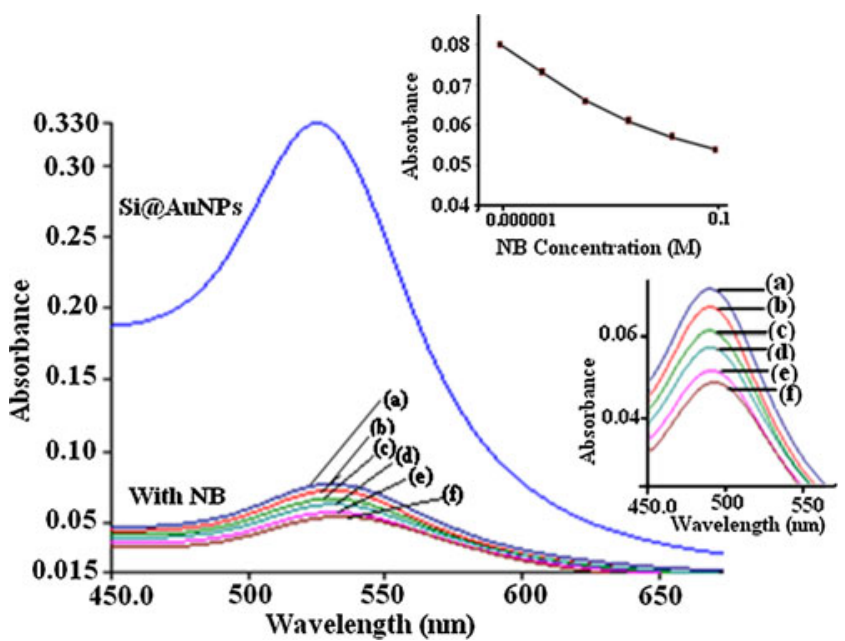

Fig. $6 \mathrm{UV}$-visible spectra of $\mathrm{SiO}_{2} / \mathrm{Au} \mathrm{NPs}$ in the absence (blue curve) and presence of (a) $10^{-6} \mathrm{M},(b) 10^{-5} \mathrm{M},(c) 10^{-4} \mathrm{M},(d) 10^{-3} \mathrm{M},(e)$ $10^{-2} \mathrm{M},(f) 10^{-1} \mathrm{M} \mathrm{NB}$

employed for designing the surface chemistry of nanostructures and electrodes to achieve the selectivity and sensitivity for the detection of TNT using fluorescence and electrochemical techniques [24-26]. This complex formation is believed to cause the damping of surface plasmon resonance due to gold core. The exact mechanism by which this occurs is not known, but the literature suggests the possibility of an increase in the imaginary part of the dielectric constant of gold [27-29]. The adsorption of NB introduces a thin layer of with the modified electron density on gold cores which produces a damping effect on SPR.

The sensing ability of $\mathrm{SiO}_{2} / \mathrm{Au}$ NPs towards NB has been determined as a function of NB concentration as shown in
Fig. 6. As the concentration of NB increased from $10^{-6}$ to $10^{-1} \mathrm{M}$, intensity of SPR of $\mathrm{SiO}_{2} / \mathrm{Au} \mathrm{NPs}$ at $530 \mathrm{~nm}$ decreased linearly (inset, Fig. 6).

\section{Electrochemical detection}

It is evident from the literature that metallic NPs can catalyze oxidation/reduction of various organic compounds [30] but they suffer the aggregation problem. To explore the capability of $\mathrm{SiO}_{2} / \mathrm{Au}$ NPs to enhance the sensitivity of the electrode towards NB via surface absorption by silica and reduction at Au cores [30-32], CV studies were performed by incubating $\mathrm{SiO}_{2} / \mathrm{Au}$ NPs-modified electrode in $0.5 \mathrm{M}$ $\mathrm{NaCl}$ electrolyte solution containing different amounts of $0.01 \mathrm{mM}$ NB.

In the absence of $\mathrm{NB}$, no reduction and oxidation peaks were observed for $\mathrm{SiO}_{2} / \mathrm{Au}$ NPs-modified electrode (Fig. 7, inset, curve c) incubated in $0.1 \mathrm{M} \mathrm{NaCl}$. With the addition of $\mathrm{NB}$ in electrolytic solution, two cathodic reduction peaks, $C_{1}(-0.74 \mathrm{~V})$ and $C_{2}(-0.45)$, and two anodic oxidation peaks, $A_{1}(-0.62 \mathrm{~V})$ and $A_{2}(0.03 \mathrm{~V})$, were observed as shown in Fig. 7 (inset, curve d). $A_{1} / C_{1}$ can be attributed to the four-electron irreversible reduction of the nitro group $\left(-\mathrm{NO}_{2}\right)$ to the hydroxylamine derivative $(-\mathrm{NHOH})$ and $A_{2} /$ $\mathrm{C}_{2}$ is assigned to the two-electron reversible oxidation of the hydroxylamine group $(-\mathrm{NHOH})$ to a nitroso group $(-\mathrm{NO})$ as shown below in Eqs. 2 and 3 [33, 34].

$$
\begin{aligned}
& -\mathrm{NO}_{2}+4 e^{-}+4 \mathrm{H}^{+} \rightarrow-\mathrm{NHOH}+\mathrm{H}_{2} \mathrm{O} \\
& -\mathrm{NHOH} \leftrightarrow-\mathrm{NO}+2 \mathrm{H}^{+}+2 e^{-}
\end{aligned}
$$

Fig. $7 \mathrm{CV}$ of $(a)$ bare $\mathrm{GC},(b)$ $\mathrm{SiO}_{2} / \mathrm{Au} \mathrm{NPs} / \mathrm{GC}$ electrode in $0.1 \mathrm{M} \mathrm{NaCl}$ solution containing $0.01 \mathrm{mM} \mathrm{NB}$, inset: $\mathrm{CV}$ of $(c)$ $\mathrm{SiO}_{2} / \mathrm{Au} \mathrm{NPs} / \mathrm{GC} \mathrm{NaCl}$ without $\mathrm{NB}$ and $(d)$ with NB $(0.01 \mathrm{mM})$

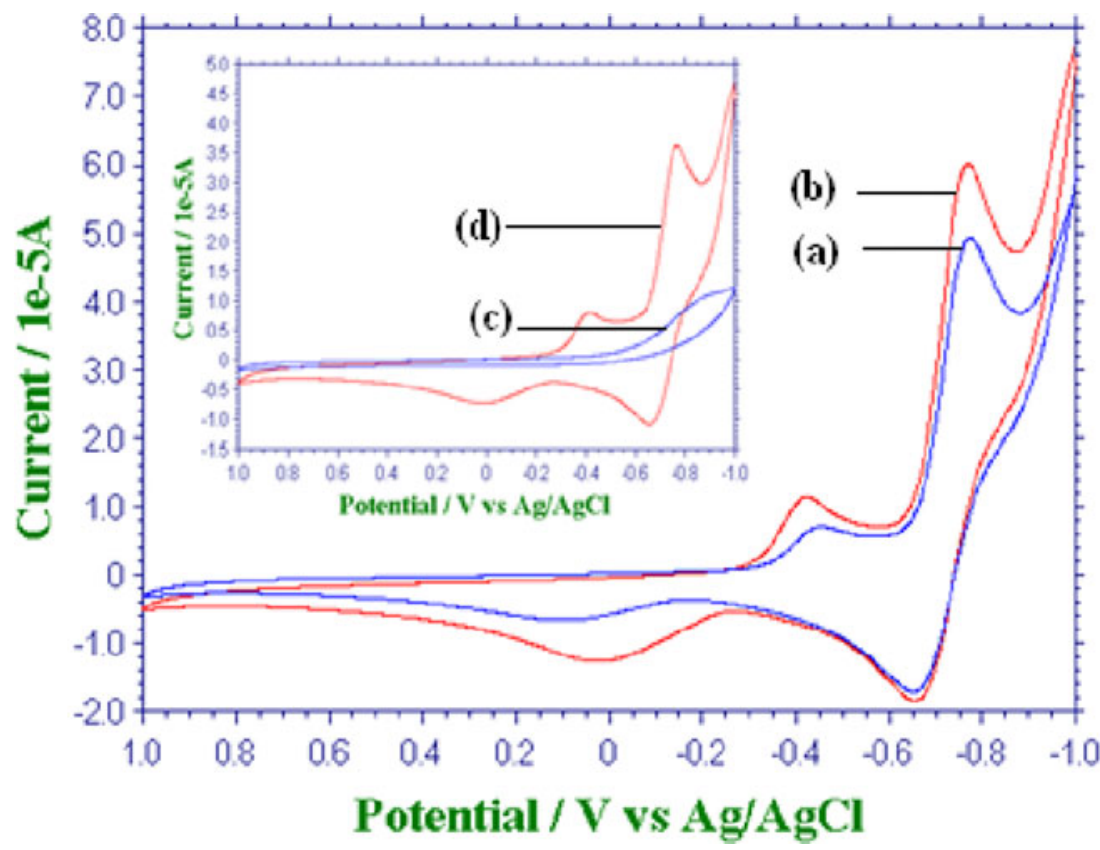



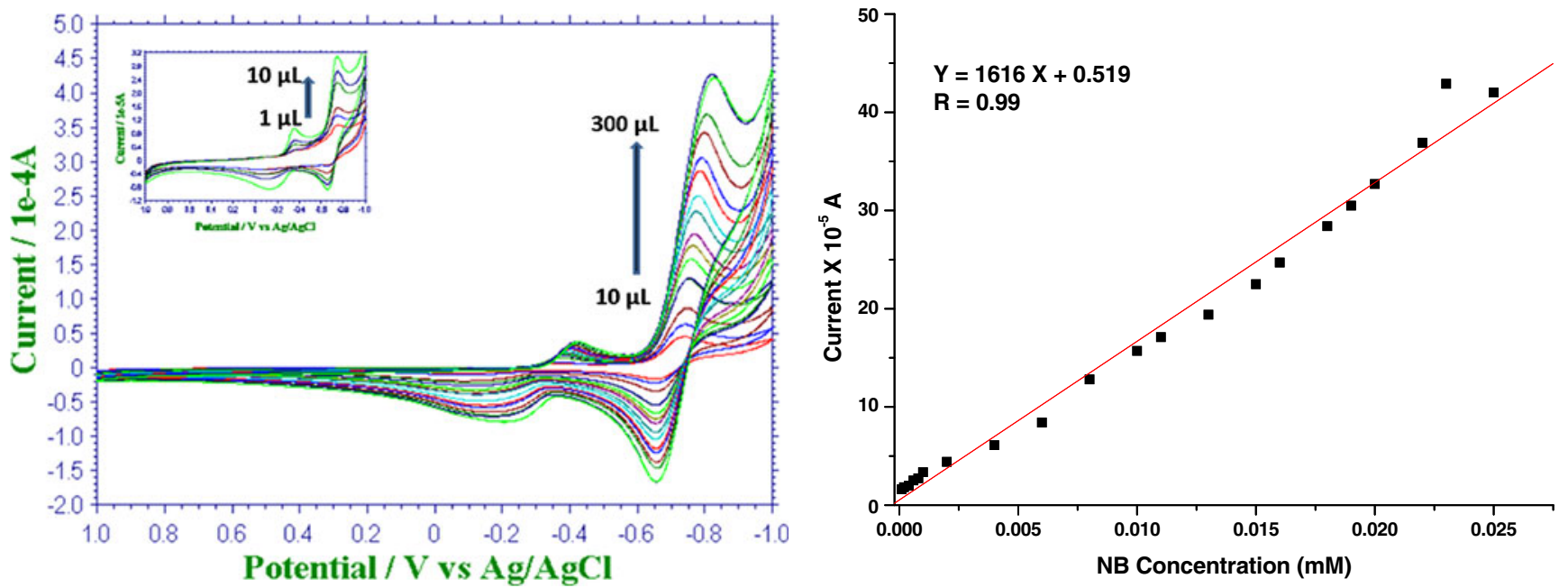

Fig. 8 (a) $\mathrm{CV}$ of $\mathrm{SiO}_{2} / \mathrm{Au} \mathrm{NPs} / \mathrm{GC}$ electrode in $0.1 \mathrm{M} \mathrm{NaCl}$ solution contacting varying amount of NB (10 to $\left.300 \mu \mathrm{l}\right)$, inset: for 1 to $10 \mu \mathrm{l}$ of $\mathrm{NB}$ and $(b)$ a relation curve between reduction peak current, $C_{1}$, and NB concentration $\left(1 \times 10^{-4}\right.$ to $\left.2.5 \times 10^{-2} \mathrm{mM}\right)$

A significant enhancement $(\sim 30 \%)$ in reduction peak current $\left(C_{1}\right)$ is observed at modified electrode $\left(\mathrm{GC} / \mathrm{SiO}_{2} / \mathrm{Au}\right.$ NPs) relative to that at bare electrode (Fig. 7, curves a and b) and is attributed to the synergic effect of surface $-\mathrm{OH}$ groups selectivity of mesoporous silica towards NB and its subsequent catalytic reduction by metallic Au cores [31,32].

Figure 8 shows the $\mathrm{CV}$ response of the modified electrode as a function of NB concentration $\left(1 \times 10^{-4}\right.$ to $2.5 \times$ $\left.10^{-2} \mathrm{mM}\right)$. A monotonic increase in peak current with an increase of NB concentration is observed. The detection limit calculated from linear response curve (Fig. 8 (b)) is found to be $12.3 \mathrm{ppb}$ and the current sensitivity is $\sim 102 \mu \mathrm{A} /$ $\mathrm{mM}\left(R^{2}=0.985\right)$. It can be seen in Fig. 8 (b) that the curve is having linearity up to $2.3 \times 10^{-2} \mathrm{mM}$ NB concentration and a kink after that. The level at which the kink is observed may be assigned as the threshold point of the sensing platform as the graph is curvilinear after this value.

Interference studies with ions $\mathrm{NO}_{3}^{-}, \mathrm{Ni}^{2+}$, and $\mathrm{Zn}^{2+}$ and phenol $(0.1 \mathrm{M})$ were done under the same experimental conditions and no interference of these species on sensor performance was observed. The selectivity of this sensing platform towards specific nitro-compound can be further introduced by modifying the silica surface with specific organic moieties [35]. The effect of other parameters such as film thickness, $\mathrm{pH}$, and temperature on sensitivity is under study.

\section{Conclusion}

Silica-coated $\mathrm{Au}$ NPs $\left(\mathrm{SiO}_{2} / \mathrm{Au} \mathrm{NPs}\right)$ have been explored as a wide-range sensitive sensing platform towards NB. Acidbase chemistry (Meisenheimer complex) between hydroxyl groups presented on the mesoporus silica surface and electron-deficient aromatic ring of NB was used for NB immobilization and subsequent catalytic reduction by metal $\mathrm{Au}$ ) core. Damping in SPR intensity of Au NPs was observed on NB immobilization, which may be explained by an increase in the imaginary part of the dielectric constant on NB adsorption. The optical detection range is observed in window $10^{-1}$ to $10^{-6} \mathrm{M}$ while electrochemical detection range is found to be in the narrow window $\left(10^{-4}\right.$ to $\left.2.5 \times 10^{-2} \mathrm{mM}\right)$ with a detection limit of $12.3 \mathrm{ppb}$ and sensitivity of $102 \mu \mathrm{A} /$ $\mathrm{mM}$ relative to bare and silica-modified electrode.

Acknowledgments Authors are thankful to Dr. Pawan Kapur, director, Central Scientific Instruments Organization, Chandigarh, for his kind permission to carry out this work.

Open Access This article is distributed under the terms of the Creative Commons Attribution License which permits any use, distribution and reproduction in any medium, provided the original author(s) and source are credited.

\section{References}

1. Zhang H-K, Liang S-X, Liu S-J (2007) Determination of nitrobenzene by differential pulse voltammetry and its application in wastewater analysis. Anal Chem 387(4):1511-1516

2. Davies L (2003) Nitrobenzene, W.H.O.T.G.o.E.H.C.f

3. Chen M, Yin Y, Tai C, Zhang Q, Liu J, Hu J, Jiang G (2006) Analyses of nitrobenzene, benzene and aniline in environmental water samples by headspace solid phase microextraction coupled with gas chromatography-mass spectrometry. Chin Sci Bull 51:1648-1651

4. Hakånsson K, Coorey RV, Zubarev RA, Talrose VL, Hakansson PJ (2000) Low-mass ions observed in plasma desorption mass spectrometry of high explosives. Mass Spectrom 35:337-346

5. Anferov VP, Mozjoukhine GV, Fisher R (2000) Pulsed spectrometer for nuclear quadrupole resonance for remote detection of nitrogen in explosives. Rev Sci Instrum 71:1656-1659 
6. Luggar RD, Farquharson MJ, Horrocks JA, Lacey RJ (1998) Multivariate analysis of statistically poor edxrd spectra for the detection of concealed explosives. J X-ray Spectrom 27:87-94

7. Rouhi AM (1997) Seeking drugs in natural products. Chem Eng News 75:14-20

8. Fujihara H, Nakai H (2001) Fullerenethiolate-functionalized gold nanoparticles: A new class of surface-confined metal-c60 nanocomposites. Langmuir 17:6393-6395

9. Nooney RI, Dhanasekaran T, Chen Y, Josephs R, Ostafin AE (2002) Self-assembled highly ordered spherical mesoporous silica/gold nanocomposites. Adv Mater 14:529-532

10. Zhang HX, Cao AM, Hu JS, Wan LJ, Lee ST (2006) Electrochemical sensor for detecting ultratrace nitroaromatic compounds using mesoporous sio2-modified electrode. Anal Chem 78:1967-1971

11. Lu Y, Yin Y, Li YZ, Xia Y (2002) Synthesis and selfassembly of au@sio2 core-shell colloids. Nano Lett 2:785-788

12. Shimizu T, Teranishi T, Hasegawa S, Miyake M (2003) Size evolution of alkanethiol-protected gold nanoparticles by heat treatment in the solid state. J Phys Chem B 107:2719-2724

13. Graf C, Blaaderen AV (2002) Metallodielectric colloidal coreshell particles for photonic applications. Langmuir 18:524-534

14. Bard AJ, Faulkner LR (1980) Techniques based on concepts of impedance In: Electrochemical methods: fundamentals and applications. Wiley, New York, pp 316-330

15. Caschera D, Federici F, Zane D, Focanti F, Curulli A, Padeletti G (2009) Gold nanoparticles modified gc electrodes: Electrochemical behaviour dependence of different neurotransmitters and molecules of biological interest on the particles size and shape. J Nanopart Res 11:1925-1936

16. Kobayashi Y, Katakami H, Mine E, Nagao D, Konno M, Liz MLM (2005) Silica coating of silver nanoparticles using a modified Stöber method. J Colloid Interface Sci 283(2):392-396

17. Oldenburg SJ, Westcott SL, Averitt RD, Halas NJ (1999) Surface enhanced raman scattering in the near infrared using metal nanoshell substrates. J Chem Phys 111:4729-4735

18. Cachet C, Stroder U, Wiart R (1982) The kinetics of zinc electrode in alkaline zincate electrolytes. Electrochim Acta 27:903-908

19. Williams DE, Asher J (1984) Measurement of low corrosion rates: Comparison of a.C. Impedance and thin layer activation methods. Corrosion Sci 24:185-196

20. Bonanni A, Pumera M, Miyahara Y (2011) Influence of gold nanoparticle size $(2-50 \mathrm{~nm})$ upon its electrochemical behavior: An electrochemical impedance spectroscopic and voltammetric study. Phys Chem Chem Phys. doi:10.1039/c0cp01209b

21. Katz E, Willner I (2003) Probing biomolecular interactions at conductive and semiconductive surfaces by impedance spectroscopy: Routes to impedimetric immunosensors, DNA-sensors, and enzyme biosensors. Electroanalysis 15:913-947
22. Curulli A, Valentini F, Viticoli M, Caschera D, Palleschi G (2005) Gold nanotubules arrays as new materials for sensing and biosensing: Synthesis and characterization. Sens Actuators B 111112:526-531

23. Zanello P (2003) Inorganic electrochemistry: Theory, practice and application, royal society of chemistry ISBN 0-85404-661-5

24. Xie C, Zhang Z, Wang D, Guan G, Gao D, Liu J (2006) Surface molecular self-assembly strategy for tnt imprinting of polymer nanowire/nanotube arrays. Anal Chem 78:8339-83346

25. Gao D, Zhang Z, Wu M, Xie C, Guan G, Wang D (2007) A surface functional monomer-directing strategy for highly dense imprinting of tnt at surface of silica nanoparticles. J Am Chem Soc 129:7859 7866

26. Guan G, Zhang Z, Wang Z, Liu B, Guo D, Xie C (2007) Singlehole hollow polymer microspheres toward specific high-capacity uptake of target species. Adv Mater 19:2370-2374

27. Mirkin CA, Letsinger RL, Mucic RC, Storhoff JJ (1996) A DNAbased method for rationally assembling nanoparticles into macroscopic materials. Nature 382:607-609

28. Linnert T, Mulvaney P, Henglein A (1993) Surface chemistry of colloidal silver: surface plasmon damping by chemisorbed iodide, hydrosulfide (SH-), and phenylthiolate. J Phys Chem 97:679-682

29. Henglein A, Meisel D (1998) Spectrophotometric Observations of the Adsorption of Organosulfur Compounds on Colloidal Silver Nanoparticles. J Phys Chem B 102:8364-8366

30. Zhu H, Ke X, Yang X, Sarina S, Liu H (2010) Reduction of nitroaromatic compounds on supported gold nanoparticles by visible and ultraviolet light. Angew Chem Int Ed 49:96579661

31. Turner MB, Golovko V, Vaughan PHO, Abdulkin P, BerenguerMurcia A, Tikhov MS, Johnson BFG, Lambert RM (2008) Selective oxidation with dioxygen by gold nanoparticle catalysts derived from 55-atom clusters. Nature 454(7207):981-983

32. Grirrane A, Corma A, GarcÃ-a H (2008) Gold-Catalyzed Synthesis of Aromatic Azo Compounds from Anilines and Nitroaromatics. Science 322(5908):1661-1664

33. Núñez-Vergara LJ, Bonta M, Navarrete-Encina PA, Squella JA (2001) Electrochemical characterization of ortho and meta-nitrotoluene derivatives in different electrolytic media. Free radical formation Electrochim Acta 46:4289-4300

34. Cavalheiro ETG, Brajter-Toth A (1999) Amperometric determination of xanthine and hypoxanthine at carbon electrodes. Effect of surface activity and the instrumental parameters on the sensitivity and the limit of detection $\mathrm{J}$ Pharm Biomed Anal 19:217-220

35. Engel Y, Elnathan R, Pevzner A, Davidi G, Flaxer E, Patolsky F (2010) Supersensitive Detection of Explosives by Silicon Nanowire Arrays. Angew Chem Int Ed 38:6830-6835 